\title{
PENGARUH TINGKAT KERAPATAN TANAMAN TERHADAP KERAGAAN DAUN, PERTUMBUHAN BIJI DAN DAYA BERKECAMBAH BENIH BEBERAPA VARIETAS SORGUM (Sorghum bicolor (L.) Moench) PADA SISTEM TUMPANGSARI DENGAN UBI KAYU (Manihot esculenta Crantz)
}

\author{
Anggi Anggrestyas Siwi, Muhammad Kamal \& Sunyoto \\ Jurusan Agroteknologi Fakultas Pertanian Universitas Lampung \\ Jl. Prof. Dr. Soemantri Brodjonegoro No. 1 Bandar Lampung 35141 \\ E-mail: anggianggrestyas@gmail.com
}

\begin{abstract}
ABSTRAK
Sorgum merupakan tanaman serealia sumber karbohidrat yang cukup penting bagi penduduk dunia. Alternatif pengembangan sorgum yaitu dengan melakukan pola tanam tumpangsari dan dengan pengaturan kerapatan tanaman. Hasil penelitian Pithaloka (2014) menunjukkan bahwa sorgum yang ditanam monokultur dengan kerapatan tinggi (3-4 tanaman per lubang) menghasilkan produksi biji per satuan luas lahan lebih tinggi dibandingkan dengan kerapatan tanaman (1-2 tanaman per lubang). Tujuan dari penelitan ini adalah (1) Mengetahui tingkat kerapatan tanaman terbaik untuk keragaan daun, pertumbuhan biji dan daya berkecambah benih sorgum pada sistem tumpangsari dengan ubikayu; (2) Mengetahui pengaruh perbedaan varietas terhadap keragaan daun, pertumbuhan biji dan daya berkecambah benih sorgum pada sistem tumpangsari dengan ubi kayu; (3) Mengetahui pengaruh interaksi antara kerapatan tanaman dan varietas terhadap keragaan daun, pertumbuhan biji, dan daya berkecambah benih sorgum pada sistem tumpangsari dengan ubikayu. Perlakuan disusun secara faktorial (3X4) dalam Rancangan Acak Kelompok (RAK) dengan tiga ulangan. Hasil penelitian menunjukkan bahwa pengaruh kerapatan tanaman terhadap keragaan daun, pertumbuhan biji dan daya berkecambah benih sorgum tergantung pada varietas. Pada kerapatan tanaman rendah (1 dan 2 tanaman per lubang) varietas Numbu memiliki jumlah biji/tanaman tertinggi dibandingkan dengan varietas Keller dan Wray, sementara pada daya berkecambah varietas Wray tertinggi dibandingkan dengan varietas Numbu dan Keller.
\end{abstract}

Kata kunci : biji, daun, kerapatan, sorgum, tumpangsari, varietas

\section{PENDAHULUAN}

Sorgum merupakan tanaman serealia sumber karbohidrat yang cukup penting bagi penduduk dunia yang menduduki urutan kelima setelah gandum, beras, jagung, dan barley (FAO, 2002). Salah satu upaya pengembangan sorgum yaitu dengan melakukan pola tanam tumpangsari . Herawati dkk. (2012) dan Kamal (2011) melaporkan bahwa sorgum dapat ditanam secara tumpangsari dengan ubikayu. Upaya lain untuk peningkatan produksi tanaman sorgum yaitu dengan pengaturan kerapatan tanaman. Hasil penelitian sebelumnya Pithaloka (2014) menunjukkan bahwa kerapatan tanaman berpengaruh terhadap pertumbuhan dan hasil sorgum yang ditanam secara monokultur. Penanaman sorgum dengan tingkat kerapatan 3 dan 4 tanaman per lubang menghasilkan produksi biomassa dan biji per tanaman lebih rendah dibandingkan dengan tingkat kerapatan 1 dan 2 tanaman per lubang, tetapi belum diketahui pengaruhnya terhadap pertumbuhan biji dan daya kecambah benih sorgum jika dilakukan penanaman secara tumpangsari dengan ubikayu.

Kerapatan tanaman berkaitan erat dengan kompetisi jumlah radiasi matahari yang diserap tanaman (Atus'sadiyah, 2004). Menurut Gardener dkk., jika kondisi tanaman terlalu rapat, akan menghambat perkembangan vegetatif dan menurunkan laju fotosintesis dan perkembangan daun.

Sorgum merupakan tanaman $\mathrm{C} 4$ yang sangat efisien dalam memanfaatkan cahaya untuk proses fotosintesis (Lawlor, 1993). Periode pengisian biji terjadi setelah tanaman menyelesaikan fase vegetatif dan memasuki fase reproduktif dimana fotosintat dialirkan kebagian tertentu tanaman dalam bentuk biji (Nurhidayah, 2008). Semakin panjang periode pengisian biji maka semakin banyak fotosintat yang disimpan dalam biji dan selanjutnya akan menentukan kualitas dari benih sorgum Hasil penelitan Pithaloka (2014) menunjukkan 
bahwa peningkatan jumlah tanaman per lubang tanam menurunkan jumlah biji per malai dan ukuran biji tanaman sorgum pada sistem monokultur.

Menurut Kamal dkk. (2014) pada sistem tumpangsari dengan ubikayu, sorgum yang ternaungi oleh tajuk ubikayu mengalami pertumbuhan yang terhambat. Hal ini menunjukkan bahwa tekanan akibat kompetisi terhadap cahaya bisa berpengaruh negatif pada metabolisme karbon dan status hara dalam tanaman.

Penelitian ini bertujuan untuk mengetahui: (1) Tingkat kerapatan tanaman terbaik untuk keragaan daun, pertumbuhan biji dan daya berkecambah benih sorgum pada sistem tumpangsari dengan ubikayu (2) Pengaruh perbedaan varietas terhadap keragaan daun, pertumbuhan biji dan daya berkecambah benih sorgum pada sistem tumpangsari dengan ubikayu (3) Pengaruh interaksi antara kerapatan tanaman dan varietas terhadap keragaan daun, pertumbuhan biji, dan daya berkecambah benih sorgum pada sistem tumpangsari dengan ubikayu.

\section{BAHAN DAN METODE}

Penelitian dilaksanakan di Kebun Percobaan Balai Pengkajian Teknologi Pertanian (BPTP) Desa Negara Ratu Kecamatan Natar, Kabupaten Lampung Selatan dari bulan Agustus sampai Desember 2014. Kebun Percobaan ini berada pada ketinggian $135 \mathrm{~m} \mathrm{dpl,}$ mempunyai jenis tanah latosol dan sebagian podsolik merah kuning (PMK), serta memiliki iklim disekitar Kebun Percobaan Natar termasuk tipe B (Schmith Firguson, 1951) dengan curah hujan rata-rata 1.786 mm/ tahun (Departemen Pertanian, 2009).

Bahan yang digunakan dalam penelitan ini adalah tiga varietas sorgum yaitu Numbu (G1), Keller (G2) dan Wray (G3). Varietas Numbu, Keller, dan Wray yang digunakan berasal dari BPPT (Balai Penelitian dan Pengkajian Pertanian) Sulusuban, Lampung Tengah. Benih ini merupakan introduksi yang diteliti oleh Prof. Dr. Soeranto Hoeman dan dibawa ke Lampung oleh Dr. Sungkono (Sungkono dkk., 2009). Varietas ubi kayu yang digunakan adalah varietas Kasetsart. Pupuk yang digunakan dalam penelitian ini adalah Urea, SP-36, dan $\mathrm{KCl}$, dengan dosis 200,100 , dan $100 \mathrm{~kg} \mathrm{ha}^{-1}$. Perlakuan disusun secara faktorial (3X4) dalam Rancangan Acak Kelompok (RAK) dengan tiga ulangan. Faktor pertama adalah kerapatan tanaman dan faktor kedua adalah varietas. Kerapatan tanam $(\mathrm{P})$ dibagi menjadi empat taraf, yaitu satu (p1), dua (p2), tiga (p3), empat (p4) tanaman/ lubang tanam. Varietas $(\mathrm{G})$ yang digunakan ada tiga, yaitu Numbu (g1), Keller (g2), dan Wray (g3). Kombinasi perlakuan berjumlah 12 yang terbagi dalam
3 kelompok sebagai ulangan, sehingga terdapat 36 satuan percobaan. Setiap satuan percobaan berukuran $5 \times 4 \mathrm{~m}$ dan ditanami ubikayu dengan jarak tanam 80 x $60 \mathrm{~cm}$. Tanaman sorgum ditanam diantara barisan tanaman ubikayu dengan jarak $20 \mathrm{~cm}$ sehingga dalam satuan percobaan terdapat 36 lubang tanaman singkong dan 120 lubang tanaman sorgum. Homogenitas data diuji dengan uji Bartlett dan aditifitas data diuji dengan uji Tukey. Bila asumsi terpenuhi data dianalisis ragam dan dilanjutkan dengan uji beda nyata terkecil (BNT) pada taraf $5 \%$.

\section{HASIL DAN PEMBAHASAN}

Dari hasil penelitian tentang keragaan daun, pertumbuhan biji, dan daya kecambah benih tanaman sorgum dengan perbedaan varietas dan kerapatan tanaman dapat dilihat pengaruhnya dari berbagai komponen keragaan daun dan komponen pertumbuhan biji sorgum.

Tabel 1 menunjukkan bahwa kerapatan tanaman memberikan pengaruh yang nyata terhadap jumlah daun pada umur 7 dan 8 mst dan penambahan jumlah daun meningkat setiap minggunya. Hal ini sejalan dengan pendapat Sirappa (2003), pertumbuhan dan perkembangan daun akan bertambah sejalan dengan pertambahan umur tanaman. Penambahan luas daun akan terhenti saat memasuki fase pembungaan. Hal ini juga sejalan dengan pendapat Haryadi (1996) bahwa jumlah daun telah mencapai maksimal yaitu berkisar antara 6-12 helai, sehingga unsur hara yang tersedia lebih ditujukan untuk pembentukan biji.

Tabel 2 menunjukkan bahwa pada kerapatan tanaman (3-4 tanaman/lubang) memiliki nilai SPAD yang rendah dibandingkan dengan kerapatan (1-2 tanaman/ lubang) dan hal ini terkait dengan intersepsi cahaya yang diterima oleh tanaman. Hal ini sejalan dengan pendapat Gardener dkk. (1991), jika kondisi tanaman terlalu rapat, akan menghambat perkembangan vegetatif dan menurunkan laju fotosintesis dan perkembangan daun. Hasil penelitian ini berbanding terbalik dengan pernyataan (Irwan dkk., 2004) yang menyatakan bahwa pertumbuhan tidak dipengaruhi secara nyata oleh kerapatan tanaman. Hal ini berkaitan satu sama lain karena daun sebagai organ produsen fotosintat utama dan sebagai bahan pembentuk biomasa tanaman dihasilkan dari proses fotosintesis yang terjadi di daun (Sitompul \& Guritno, 1995). Kemampuan tanaman untuk melakukan fotosintesis sangat ditentukan oleh luas daun (Gardener dkk., 1991).

Tabel 3 dan 4 menunjukkan bahwa bahwa kerapatan tanaman memberikan pengaruh yang nyata 
Tabel 1. Pengaruh varietas dan kerapatan tanaman terhadap jumlah daun tanaman sorgum pada umur 5,7, dan 8 mst.

\begin{tabular}{|c|c|c|c|}
\hline \multirow{2}{*}{ Perlakuan } & \multicolumn{3}{|c|}{ Umur Tanaman (mst) } \\
\hline & 5 & 7 & 8 \\
\hline Varietas Sorgum & \multicolumn{3}{|c|}{. } \\
\hline Numbu & $4,72 \mathrm{~b}$ & $6,87 \mathrm{a}$ & $8,50 \mathrm{a}$ \\
\hline Keller & $4,75 \mathrm{~b}$ & $6,88 \mathrm{a}$ & $8,21 \mathrm{a}$ \\
\hline Wray & $5,08 \mathrm{a}$ & 7,16 a & $8,39 \mathrm{a}$ \\
\hline BNT 5\% & 0,30 & 0,34 & 0,60 \\
\hline \multicolumn{4}{|l|}{$\begin{array}{l}\text { Kerapatan } \\
\text { (tanaman/lubang) }\end{array}$} \\
\hline 1 & $4,94 \mathrm{a}$ & $7,25 \mathrm{a}$ & $8,75 \mathrm{a}$ \\
\hline 2 & $4,96 \mathrm{a}$ & 7,19 a & $8,71 \mathrm{a}$ \\
\hline 3 & $4,79 \mathrm{a}$ & $6,73 \mathrm{~b}$ & $7,96 \mathrm{~b}$ \\
\hline 4 & $4,71 \mathrm{a}$ & $6,70 \mathrm{~b}$ & $8,04 \mathrm{ab}$ \\
\hline BNT 5\% & 0,35 & 0,40 & 0,70 \\
\hline
\end{tabular}

Keterangan : Angka yang diikuti huruf yang sama dalam setiap kolom dan perlakuan tidak berbeda nyata berdasarkan BNT $5 \%$.

Tabel 2. Pengaruh varietas dan kerapatan tanaman terhadap tingkat kehijauan daun tanaman sorgum pada umur 4, 5, 6, 7 dan 8 mst.

\begin{tabular}{|c|c|c|c|c|c|}
\hline \multirow{2}{*}{ Perlakuan } & \multicolumn{5}{|c|}{ Umur Tanaman (mst) } \\
\hline & 4 & 5 & 6 & 7 & 8 \\
\hline \multicolumn{6}{|l|}{$\begin{array}{l}\text { Varietas } \\
\text { Sorgum }\end{array}$} \\
\hline Numbu & $33,27 \mathrm{a}$ & $31,89 \mathrm{~b}$ & $35,76 \mathrm{a}$ & $35,37 \mathrm{a}$ & $36,73 a$ \\
\hline Keller & $34,24 \mathrm{a}$ & $33,92 \mathrm{a}$ & $36,55 \mathrm{a}$ & $35,97 \mathrm{a}$ & $35,66 \mathrm{a}$ \\
\hline Wray & $34,65 \mathrm{a}$ & $32,62 \mathrm{ab}$ & $35,69 \mathrm{a}$ & $35,08 \mathrm{a}$ & $35,64 \mathrm{a}$ \\
\hline BNT 5\% & 3,28 & 1,50 & 1,80 & 2,04 & 1,87 \\
\hline \multicolumn{6}{|c|}{$\begin{array}{l}\text { Kerapatan } \\
\text { (tanaman/lubang) }\end{array}$} \\
\hline 1 & $34,65 \mathrm{a}$ & $34,38 \mathrm{a}$ & $39,86 \mathrm{a}$ & $39,56 \mathrm{a}$ & $39,17 \mathrm{a}$ \\
\hline 2 & 34,68 a & $33,56 \mathrm{ab}$ & $36,75 \mathrm{~b}$ & $36,09 \mathrm{~b}$ & $36,78 \mathrm{~b}$ \\
\hline 3 & 33,49 a & $32,39 \mathrm{bc}$ & $35,24 \mathrm{bc}$ & $34,36 \mathrm{~b}$ & $34,37 \mathrm{c}$ \\
\hline 4 & $33,40 \mathrm{a}$ & $30,90 \mathrm{c}$ & $33,49 \mathrm{c}$ & $31,81 \mathrm{c}$ & $33,71 \mathrm{c}$ \\
\hline BNT 5\% & 3,84 & 1,74 & 2,08 & 2,35 & 2,15 \\
\hline
\end{tabular}

Keterangan : Angka yang diikuti huruf yang sama dalam setiap kolom dan perlakuan tidak berbeda nyata berdasarkan BNT $5 \%$.

terhadap jumlah biji per malai dan bobot biji per malai. Pada kerapatan tanaman rendah 1 dan 2 tanaman/ lubang menunjukkan hasil yang lebih baik dibandingkan dengan kerapatan tanaman tinggi 3 , dan 4 tanaman/ lubang. Hal ini selaras dengan pernyataan Subandi dkk
(2001) yang dikutip oleh Tabri (2009), dengan meningkatnya populasi tanaman maka ukuran atau bobot biji menjadi berkurang. Hal ini disebabkan adanya persaingan dalam hal cahaya, air , udara, dan unsur hara yang sangat dibutuhkan tanaman. Hal ini juga sejalan 
Tabel 3. Pengaruh interaksi antara kerapatan tanaman dan varietas terhadap jumlah biji per malai tanaman sorgum pada umur 40 hsb.

\begin{tabular}{|c|c|c|c|c|c|}
\hline \multirow{3}{*}{ Varietas Sorgum } & \multicolumn{4}{|c|}{ Kerapatan (tanaman/lubang) } & \multirow[b]{2}{*}{ BNT $5 \%$} \\
\hline & 1 & 2 & 3 & 4 & \\
\hline & \multicolumn{4}{|c|}{ 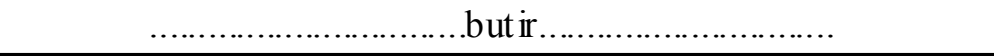 } & \\
\hline Numbu & $\begin{array}{c}1313,33 \mathrm{a} \\
\mathrm{A}\end{array}$ & $\begin{array}{c}938,50 \mathrm{~b} \\
\mathrm{~B}\end{array}$ & $\begin{array}{c}587,78 \mathrm{c} \\
\mathrm{B}\end{array}$ & $\begin{array}{c}486,00 \mathrm{c} \\
\mathrm{B}\end{array}$ & 129,61 \\
\hline Keller & $\begin{array}{c}1244,33 \mathrm{a} \\
\mathrm{A}\end{array}$ & $\begin{array}{c}1121,33 \mathrm{a} \\
\mathrm{A}\end{array}$ & $\begin{array}{c}758,67 \mathrm{~b} \\
\mathrm{~A}\end{array}$ & $\begin{array}{c}591,83 \mathrm{c} \\
\mathrm{A}\end{array}$ & \\
\hline Wray & $\begin{array}{c}785,33 \text { a } \\
\text { B }\end{array}$ & $\begin{array}{c}657,67 \mathrm{a} \\
\mathrm{C}\end{array}$ & $\begin{array}{c}515,78 \mathrm{~b} \\
\mathrm{~B}\end{array}$ & $\begin{array}{c}412,67 \mathrm{~b} \\
\mathrm{~B}\end{array}$ & \\
\hline BNT 5\% & 78,28 & & & & \\
\hline
\end{tabular}

Keterangan : Angka yang diikuti huruf yang sama tidak berbeda nyata berdasarkan uji BNT 5\%. Huruf besar perbandingan vertikal dan huruf kecil perbandingan horizontal.

Tabe1 4. Pengaruh interaksi antara kerapatan tanaman dan varietas terhadap bobot biji per malai tanaman sorgum pada umur $40 \mathrm{hsb}$.

\begin{tabular}{|c|c|c|c|c|c|}
\hline \multirow{3}{*}{ Varietas Sorgum } & \multicolumn{4}{|c|}{ Kerapatan (tanaman/lubang) } & \multirow{3}{*}{ BNT 5\% } \\
\hline & 1 & 2 & 3 & 4 & \\
\hline & \multicolumn{4}{|c|}{ 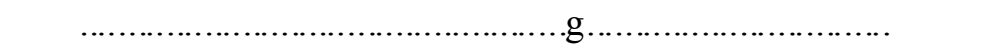 } & \\
\hline Numbu & $\begin{array}{c}36,64 \mathrm{a} \\
\mathrm{A}\end{array}$ & $\begin{array}{c}28,33 \mathrm{~b} \\
\mathrm{~A}\end{array}$ & $\begin{array}{c}24,32 \mathrm{c} \\
\mathrm{A}\end{array}$ & $\begin{array}{c}14,072 \mathrm{~d} \\
\mathrm{~A}\end{array}$ & \\
\hline Keller & $\begin{array}{c}25,91 \mathrm{a} \\
\mathrm{B}\end{array}$ & $\begin{array}{c}20,58 \mathrm{~b} \\
\mathrm{~B}\end{array}$ & $\begin{array}{c}14,64 \mathrm{c} \\
\mathrm{B}\end{array}$ & $\begin{array}{c}13,69 \mathrm{c} \\
\mathrm{A}\end{array}$ & 3,78 \\
\hline Wray & $\begin{array}{c}20,90 \mathrm{a} \\
\mathrm{C}\end{array}$ & $\begin{array}{c}16,26 \mathrm{~b} \\
\mathrm{C}\end{array}$ & $\begin{array}{c}14,73 \mathrm{~b} \\
\mathrm{~B}\end{array}$ & $\begin{array}{c}6,34 \mathrm{c} \\
\mathrm{B}\end{array}$ & \\
\hline
\end{tabular}

BNT $5 \%$

2,28

Keterangan : Angka yang diikuti huruf yang sama tidak berbeda nyata berdasarkan uji BNT 5\%. Huruf besar perbandingan vertikal dan huruf kecil perbandingan horizontal.

dengan penelitian sebelumnya oleh Pithaloka (2014), bahwa kerapatan tanaman rendah (1-2 tanaman/lubang) memiliki jumlah biji/malai, bobot biji/malai lebih tinggi dibandingkan dengan kerapatan tanaman tinggi (3-4 tanaman/lubang) yang ditanam monokultur disebabkan terjadinya kompetisi yang tinggi pada kerapatan tanaman (3-4 tanaman/lubang). Pada komponen pertumbuhan biji sorgum varietas berpegaruh nyata terhadap jumlah biji/ malai (Tabel 3), bobot biji ( Tabel4) dan daya kecambah (Tabel 5). Hal ini sesuai dengan pernyataan Sitompul (2003) yang menyatakan bahwa perbedaan susunan genetik merupakan salah satu faktor penyebab keragaman penampilan tanaman.

Daya berkecambah benih sorgum juga terkait dengan pertumbuhan biji, hal ini sejalan dengan pendapat
(Sutopo, 2010) yang menyatakan bahwa semakin berat benih 1000 biji kemungkinan kecepatan kecambah benihh semakin meningkat.Pada Tabel 5. dapat dilihat kerapatan tanaman tidak berpengaruh terhadap daya berkecambah benih karena pada variabel ukuran/bobot biji sesuai pernyataan Pitaloka (2014), jika pada kerapatan tanaman tinggi (3 dan 4 tanaman/lubang) bobot biji/malai tanaman sorgum akan lebih rendah dibandingkan dengan kerapatan tanaman rendah (1 dan 2 tanaman/lubang). Pada kerapatan tinggi (3 dan 4 tanaman/lubang) tanaman akan mengkompensasi supaya tidak punah dan memiliki generasi yang akan datang, dimana bobot biji akan sama pada tingkat kerapatan rendah ( 1 dan 2 tanaman/lubang), sehingga kemampuan berkecambah pun sama antara kerapatan tanaman tinggi 
Tabel 5. Pengaruh interaksi antara kerapatan tanaman dan varietas terhadap daya berkecambah biji sorgum pada $40 \mathrm{hsb}$.

\begin{tabular}{|c|c|c|c|c|c|}
\hline \multirow{3}{*}{ Varietas Sorgum } & \multicolumn{4}{|c|}{ Kerapatan (tanaman/lubang) } & \multirow{3}{*}{ BNT $5 \%$} \\
\hline & 1 & 2 & 3 & 4 & \\
\hline & \multicolumn{4}{|c|}{ 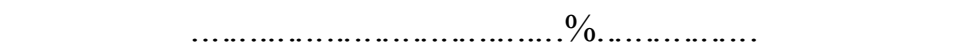 } & \\
\hline Numbu & $\begin{array}{c}88,33 \mathrm{a} \\
\mathrm{B}\end{array}$ & $\begin{array}{c}79,00 \mathrm{ab} \\
\mathrm{B}\end{array}$ & $\begin{array}{c}85,67 \mathrm{ab} \\
\mathrm{AB}\end{array}$ & $\begin{array}{c}86,00 \mathrm{a} \\
\mathrm{B}\end{array}$ & \\
\hline Keller & $\begin{array}{c}94,00 \mathrm{a} \\
\mathrm{A}\end{array}$ & $\begin{array}{c}94,00 \mathrm{a} \\
\mathrm{A}\end{array}$ & $\begin{array}{c}90,00 \mathrm{a} \\
\mathrm{A}\end{array}$ & $\begin{array}{c}93,67 \mathrm{a} \\
\mathrm{A}\end{array}$ & 7,17 \\
\hline Wray & $\begin{array}{c}95,00 \mathrm{a} \\
\mathrm{A}\end{array}$ & $\begin{array}{c}94,33 \mathrm{a} \\
\mathrm{A}\end{array}$ & $\begin{array}{c}91,33 \mathrm{a} \\
\mathrm{A}\end{array}$ & $\begin{array}{c}86,67 \mathrm{ab} \\
\mathrm{B}\end{array}$ & \\
\hline BNT 5\% & 4,33 & & & & \\
\hline
\end{tabular}

Keterangan : Angka yang diikuti huruf yang sama tidak berbeda nyata berdasarkan uji BNT 5\%. Huruf besar perbandingan vertikal dan huruf kecil perbandingan horizontal.

(3 dan 4 tanaman/lubang) dengan kerapatan tanaman rendah (1 dan 2 tanaman tinggi).

Penerapan sistem teknologi budidaya dengan pengaturan kerapatan tanaman dengan mengkombinasikan varietas-varietas unggul yang memiliki kelebihan susunan genetik masing-masing dengan sistem tumpang sari akan berdampak positif terhadap optimalisasi penggunaan lahan. Varietas Numbu dengan kerapatan tanaman tinggi (3 dan 4 tanaman/ lubang) akan menghasilkan bobot biji yang lebih tinggi yaitu 1,45 ton dan 1,12 ton/ha dibandingkan dengan kerapatan tanam rendah (1 dan 2 tanaman/lubang). Hal ini akan sangat menguntungkan apabila diterapkan dimasyarakat. Penggunaan Varietas untuk produksi benih dianjurkan untuk menggunakan varietas Wray dengan kombinasi kerapatan rendah (1 dan 2 tanaman/ lubang) lebih baik dibandingkan dengan kerapatan tinggi (3 dan 4 tanaman/lubang), yang menghasilkan persentase daya berkecambah lebih tinggi dibandingkan varietas Keller dan Numbu.

\section{KESIMPULAN}

Berdasarkan hasil penelitian, maka dapat disimpulkan bahwa kerapatan tanaman rendah (1 dan 2 tanaman/lubang) menghasilkan keragaan daun dan pertumbuhan biji yang lebih tinggi dibandingkan dengan kerapatan tinggi (3 dan 4 tanaman/lubang). Varietas Numbu lebih tinggi dibandingkan dengan varietas Keller dan Wray dalam komponen pertumbuhan biji yaitu jumlah biji/tanaman dan bobot biji/tanaman. Pengaruh kerapatan tanaman terhadap keragaan daun, pertumbuhan biji dan daya berkecambah benih sorgum tergantung pada varietas. Pada kerapatan tanaman rendah (1 dan 2 tanaman/lubang) varietas Numbu memiliki jumlah biji/ tanaman tertinggi dibandingkan dengan varietas Keller dan Wray, sementara pada daya berkecambah varietas Wray tertinggi dibandingkan dengan varietas Numbu dan Keller.

\section{DAFTAR PUSTAKA}

Atus'sadiyah, M. 2004. Pertumbuhan dan Hasil Tanaman Buncis (Phaseolus vulgaris L) Tipe Tegak Pada Berbagai Variasi Kepadatan Tanaman dan Waktu Pemangkasan Pucuk. Skripsi. Fakultas Pertanian Universitas Brawijaya. Malang.

Departemen Pertanian, 2009. Sekilas Kebun Percobaan Natar. Balai Pengkajian Teknologi Pertanian. Lampung.

FAO, Agricultural Departement.2002. Sweet Sorghum in China. World Food Summit, 10-13 june 2002.(http://www.fao.org/agl). Diakses tanggal 28 Agustus 2014

Gardner, F.P., R.B. Pearce, dan R.L. Mitchell. 1991. Fisiologi Tanaman Budidaya Terjemahan Herawati Susilo. Universitas Indonesia Press. Jakarta. 428 hal.

Haryadi.S.S., 1996. PengantarAgronomi. PT. Gramedias Pustaka Utama. Jakarta. 
Hamim, H., R. Larasati dan M. Kamal. 2012. Analisis komponen hasil sorgum yang ditanam tumpang sari dengan ubi kayu dan waktu tanam berbeda. Prosiding Simposium dan Seminar Bersama PERAGI-PERHORTIPERIPI-HIGI Mendukung Kedaulatan Pangan dan Energi yang Berkelanjutan.p 91- 94. Bogor, 1-2 Mei 2012.

Irwan, W., A. Wahyudin, R. Susilawati dan T. Nurmala, 2004. Interaksi jarak tanam dan jenis pupuk kandang terhadap komponen hasil dan kadar tepung sorgum (Sorghum bicolor (L.) Moench) pada Inseptisol di Jatinangor. Jurnal Budidaya Tanaman. 4: 128-136.

Kamal, M. 2011. Kajian Sinergi Pemanfaatan Cahaya dan Nitrogen Dalam Produksi Tanaman Pangan. Pidato ilmiah dalam rangka pengukuhan guru besar dalam bidang ilmu tanaman Fakultas Pertanian Univeritas Lampung di Bandar Lampung tanggal 23 Febuari 2011. Penerbit Universitas Lampung, Bandar Lampung. $68 \mathrm{hlm}$.

Kamal, M., M.S. Hadi, E. Heriyanto, Jumarko dan Ashadi. 2014. Grain Yield, and Nutrient and Starch Content of Sorghum (Sorghum bicolor (L.) Moench) Genotypes as Affected by Date of Intercropping with Cassava in Lampung, Indonesia. J. ISSAAS . 20, 64-76.

Lawlor, D.W. 1993. Photosynthesis: Molecular, Physiological and Environmental Processes. 2nd Ed. Longman Scientific \& Technical. England. pp 12-15.

Nurhidayah , E. 2008. Kajian Genotipe Periode Pengisian Biji, Kualitas Benih dan Ukuran Benih Berbagai Genotipe Sorgum (Sorghum bicolor (L.) Moench). Skripsi. Fakultas Pertanian. Universitas Lampung. Bandar Lampung.
Pithaloka, S. 2014. Pengaruh Kerapatan Tanaman Terhadap Pertumbuhan dan Hasil Beberapa Varietas Sorgum (Sorgum bicolor (L.) Moench). Skripsi. Fakultas Pertanian Universitas Lampung. Bandar Lampung.

Schmidt, F.H. and Ferguson, J.H.A. 1951.Rainfall Types Based on Wet and Dry Period Rations for Indonesia and Western New Guinea Verh Djawatan Mety. Dan Geofisik, Jakarta, Indonesia, $700 \mathrm{pp}$.

Sirappa, M. P. 2003. Prospek Pengembangan Sorgum di Indonesia Sebagai Komoditas Alternatif untuk Pangan. Pakan dan Industri.Jurnal Litbang Pertanian.

Sitompul, S.M.P.2003. Prospek Pengembangan Sorgum di Indonesia Sebagai Komoditas Alternatif untuk Pangan, Pakan, dan Industri. Jurnal Litbang Pertanian. 22 (4): 133-140.

Sitompul, S. M. dan B. Guritno. 1995.Analisis Pertumbuhan Tanaman. UGM Press. Yogyakarta.

Sutopo, L.2010. Teknologi Benih. PT. Raja Grafindo Persada. Jakarta. $237 \mathrm{hlm}$.

Tabri, F. 2009. Teknologi Biomas Jagung Melalui Peningkatan Populasi Tanaman. Prosiding Seminar Serealia 2009. Balai Penelitian Tanaman Serealia. Sulawesi Selatan.

Sungkono, Trikoesoemaningtyas, D.Wirnas, D. Soepandie, S. Human dan M.A. Yudiarto, 2009. Pendugaan Parameter Genetik dan Seleksi Galur Mutan Sorgum (Sorghum bicolor (L.) Moench) di Tanah Masam. J. Agron. Indonesia. 37(3): 220-225. 